\title{
Look out for rough drafts of mammal genomes
}

\section{WASHINGTON DC}

The scaly pangolin, the wide-eyed bushbaby and a deadly mosquito are among 13 new organisms to be sequenced by the US National Human Genome Research Institute (NHGRI) in Bethesda, Maryland.

But not all of their genomes will be read completely. The agency, which has 61 genomes finished or in the pipeline, said on 7 June that it will fund a strategy called low-density draft coverage for eight of the mammals in the new batch, including the pangolin (Manis spp.) and bushbaby (Otolemur garnettii). The approach has been used on six animals already, including a hedgehog-like animal known as a tenrec (Echinops telfairi). The process can reveal mammals' evolution by providing information from distantly related species.

Low-density coverage will help biologists to find the genome regions that have changed least through time. But many

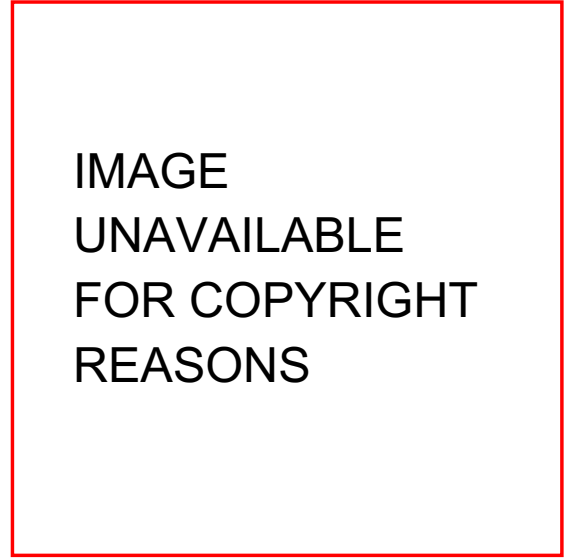

The bushbaby's DNA sequence may be a bit skimpy.

scientists are disappointed because it may not address one of the hot areas of genomics: large differences in genomes, such as rearrangements of DNA or changes in the number of copies of particular regions of DNA (see Nature 435, 252-253; 2005). Finding such regions is likely to require high-quality, complete genome assemblies. To address this, the NHGRI says it will fund a project to sequence part of the gibbon genome, which seems to contain lots of genomic rearrangements.

But genome biologists are pleased, at least, that new species are up for sequencing. They accept that, in many cases, low-density coverage is the best they will get for the time being. "At today's cost and effort we're not going to see a finished genome for the tenrec," says Richard Gibbs, director of the Human Genome Sequencing Center at Baylor College of Medicine in Houston, Texas. But he says he hopes to find out more about the tenrec and its relatives as sequencing costs drop. "This is a beginning, not an end, to exploring those other species." Erika Check 